\title{
DIGITALCOMMONS
}

@WAYNESTATE —

Wayne State University

Law Faculty Research Publications

Law School

$1-1-1991$

\section{Contingency and Community in Normative Practice}

Steven L. Winter

Wayne State University, swinter@wayne.edu

\section{Recommended Citation}

Steven L. Winter, Contingency and Community in Normative Practice, 139 U. Pa. L. Rev. 963 (1991). doi: 10.2307/3312377 Available at: http://digitalcommons.wayne.edu/lawfrp/4

This Article is brought to you for free and open access by the Law School at DigitalCommons@WayneState. It has been accepted for inclusion in Law Faculty Research Publications by an authorized administrator of DigitalCommons@WayneState. 


\section{STEVEN L. WINTER $†$}

\section{NO TURN ON RED}

This school year, I am teaching in the city where I grew up. I haven't lived here for seventeen years, but there is a welcome familiarity to the streets, parks, and other landmarks of my childhood and adolescence. One thing at least has changed rather dramatically. ${ }^{1}$ The local drivers are more erratic and unpredictable than when I first learned to drive these streets some twenty years ago. The occasional left turn from a right lane is disconcerting enough. But, far worse, the local drivers seem to treat a red light as a kind of advisory opinion from the traffic department. Even though $I$ learned a few things about erratic driving during four years in Miami, I have had to make some adjustments to get around without mishaps.

My route to and from the law school takes me down the city's main street. On my way home one evening, I stopped for a red light at a familiar spot about one hundred feet from the street where one of my grade school classmates used to live. While I waited for the light to change, I noticed that the cable which supports the light also supports a sign that reads "No Turn on Red." This is not unusual in itself. There are many such signs on street corners all over the city. Many are at intersections where there are likely to be children nearby, and this particular intersection is near a housing project.

But there is one thing truly odd about this sign: It is posted at a three-way intersection where the only side street is a one way street that enters from the left. Two rather conspicuous "Do Not

* (C) Copyright 1991, Steven L. Winter.

+ Professor, University of Miami School of Law; Visiting Professor, Yale Law School. I am indebted to Lynn Winter who not only helped with the research, but also helped shape the way in which I have come to understand these issues. My thanks also to Bruce Ackerman, Owen Fiss, Mark Johnson, Tony Kronman, Frank Michelman, Jeremy Paul, Pierre Schlag, and the participants in the legal theory workshops at the Duke and University of Toronto Law Schools.

1 Well, actually, some other things have changed, too. The city is more scarred by poverty, drugs, and violence. See Finnegan, $A$ Reporter at Large: Out There-I, NEW YORKER, Sept. 10, 1990, at 51. But, then, my argument will be that these phenomena are very much related. 
Enter" signs are posted on that corner. The closest right turn is almost one hundred feet past the light, into the street where my classmate once lived. While I waited for the light to change, I marvelled at this "No Turn on Red" sign. What possibly could have led the traffic department to place it there? Had drivers been making a left turn on red, heading the wrong way down the entering one way street? Or had they been going through the red light, proceeding the hundred feet to the next corner, and then turning right? And if they had been doing either of those things, was it remotely plausible that one more sign proclaiming "No Turn on Red" would have any effect whatsoever on their (mis)behavior?

I don't want you to think that such exercises in legal futility are a particular peccadillo of my hometown. My wife and I watched an analogous set of developments when we were living in Miami. Florida law prohibits the carrying of a concealed weapon without a license. Prior to 1987 , licensing was left to the individual counties pursuant to minimum standards set out in the state statute. ${ }^{2}$ Under this regime, the two large urban counties in the southern portion of the state-Dade (which includes Miami) and Broward (which includes Fort Lauderdale)-had relatively restrictive gun licensing ordinances. The more rural counties to the north had relatively lax provisions. In 1987, the state legislature amended the law to provide for a state-wide licensing system to be administered by the Florida Department of State under more detailed standards spelled out in the statute. ${ }^{3}$ The net effect of the change was to tighten restrictions in the northern, rural counties but substantially to liberalize those in the southern, urban counties. As a result, many more Dade and Broward residents were able quickly to obtain handguns. We watched nightly as the local news programs showed scene after scene of the long lines and packed houses at local gun stores and target practice ranges.

What followed was entirely predictable. As the number of guns in Florida households increased, so did the incidents in which small children found mommy's or daddy's gun and accidentally shot themselves, their siblings, or their playmates. ${ }^{4}$ Despite the grim statistics, the number of handguns continued to increase. By the

${ }^{2}$ See FLA. STAT. ANN. \$ 790.05-.06 (West 1976).

${ }^{3}$ See id. $\$ 790.06$ (West Supp. 1990).

4 See, e.g., Fatal Shootings of Young People on the Rise in Florida, N.Y. Times, Oct. 10, 1988 , at AI1, col. 1 (reporting 37 fatal shootings of children in Dade county in the first three quarters of 1988, compared to 24 in all of 1987). 
summer of 1989, The New York Times reported that "60 percent of [Florida] households have at least one gun, a rate that is tied with that in Texas as the highest in the country. ${ }^{.5}$ Then, in a barrage of national news coverage, the inevitable denouement: In a two week period, five children were injured or killed with their parents' guns. ${ }^{6}$ There was intense pressure to do something. After first opposing any change in the gun laws, the governor reversed position and called the legislature into special session. The legislature promptly found

that a tragically large number of Florida children have been accidentally killed or seriously injured by negligently stored firearms; that placing firearms within the reach or easy access of children is irresponsible, encourages such accidents, and should be prohibited; and that legislative action is necessary to protect the safety of our children. ${ }^{7}$

It acted accordingly, mandating safe storage of all loaded firearms to which a minor might gain access. ${ }^{8}$ To make sure that parents would be aware of their responsibility not to leave a loaded gun where a child might find it, the legislature required retailers to post and deliver written warnings to the purchasers of all guns. ${ }^{9}$ Failure to comply with the storage requirements was made a second degree misdemeanor punishable by sixty days imprisonment and a $\$ 500$ fine. ${ }^{10}$ But this provision has a catch, for it applies only if a minor actually gains access to a weapon and, without supervision, handles it "[i]n a public place . . . or [i]n a rude, careless, angry, or threatening manner. ${ }^{n 11}$ As a practical matter, this proviso means that the authorities are unlikely to discover and prosecute a violation except when a child is actually injured or killed.

Now, I am not fortunate enough to be a parent yet. Nevertheless, it strikes me that, as a deterrent, sixty days and $\$ 500$ pales in comparison to the prospect that one's child might be injured or

${ }^{5}$ Schmalz, Children Shooting Children: Move is on for Gun Control, N.Y. Times, June $18,1989, \S 1$, at 20 , col. 5 .

${ }^{6}$ See id.

7 Fla. Stat. ANN. § 790.173(1) (West Supp. 1990).

${ }^{8}$ See id. \$790.174(1).

${ }^{9}$ See id. \$ 790.175(1)-(2). The warning reads: "IT IS UNLAWFUL, AND PUNISHABLE BY IMPRISONMENT AND FINE, FOR ANY ADULT TO STORE OR LEAVE A FIREARM IN ANY PLACE WITHIN THE REACH OR EASY ACCESS OF A MINOR.” Id. § 790.175(1).

${ }^{10}$ See id. $\$ \S 790.174(2), 775.082(4), 775.083(1)(\mathrm{e})$.

11 Id. $\$ 790.174(2)$. 
killed by a handgun-let alone one's own. I recognize, of course, that parents don't expect their children to find their guns; and they certainly don't envision their children shooting themselves, their siblings, or their playmates. But, by the very same token, they cannot therefore expect that they will be charged, convicted, and sentenced under the statute: In order for there to be a violation under the provision, a child must in fact find the gun. Thus, parents who do not have the foresight to anticipate the danger to their children could not possibly be deterred by the statute. And, conversely, parents with the insight to recognize that they could be liable for the statutory penalty of two months in jail already will be deterred by the prospect that their children might be injured or killed. What, then, does this law accomplish? ${ }^{12}$

In its own way, each of these examples typifies the predicament of contemporary normativity. To the degree that these particular cases seem exaggerated, they only cast in bas-relief the fundamental problems that limit and afflict all forms of normative practice. I examine these problems under the general rubric of "community." My claim is that both the success and the very coherence of normative practice are contingent upon community. But the concept of "community" that I will employ in this argument is not the conventional one that understands community primarily as a matter of political organization, geographic location, or consciously shared creed. Rather, my claim is that the social phenomena that correspond with each of these more conventional understandings are themselves possible only because community is first and foremost a cognitive phenomenon. In this view, what is referred to as a community is a group identification (whether partial or complete, self-conscious or not) that is a function or end product of common ways of understanding and living in a world. To put it another way, "community" is the name we give to a group of people

12 It may be that the statute accomplishes some non-regulatory purposes, as I will discuss shortly.

An intelligently drawn regulatory statute could have made criminal the negligent storage of a firearm per se-that is, without regard to whether a child actually gains access to the weapon. But that would have required some effective investigatory and enforcement mechanisms. The Florida legislature, however, was emphatic about its distaste for that option. In its specification of legislative findings and intent, it stated: "Nothing in this act shall be construed to reduce or limit any existing right to purchase and own firearms, or to provide authority to any state or local agency to infringe upon the privacy of any farnily, home, or business, except by lawful warrant." Id. $\S 790.173(2)$. 
who share a paradigm, ${ }^{13}$ a nomos, ${ }^{14}$ a culture,,$^{15}$ or a worldview. ${ }^{16}$

In large part, my argument will consist in the development and explication of just what I mean by this notion of community as a cognitive phenomenon. My premise, however, is that the internal determinants of community-and, thus, of all forms of normative practice-must be understood in terms of the cognitive processes of internalization and imagination. We can begin the analysis by examining the traffic sign and gun control anecdotes to see what they reveal about the role that these two processes play in the law's effort to regulate behavior.

The anecdote about the traffic sign illustrates the importance of internalization to the effective operation of law: The traffic sign will work only to the extent that drivers have already developed a habit of conformity with the rules of the road or internalized an ethic of compliance with legal directives. ${ }^{17}$ This is yet more clear in the

${ }^{13}$ See T. KUHN, THE STRUCTURE OF SCIENTIFIC REVOlUtions 11 (2d ed. 1970); Kuhn, Second Thoughts on Paradigms, in THE STRUCTURE OF SCIENTIFIC THEORIES 459, 460 (F. Suppe ed. 1974) ("A paradigm is what the members of a scientific community, and they alone, share. Conversely, it is their possession of a common paradigm that constitutes a scientific community of a group of otherwise disparate men.").

${ }^{14}$ See Cover, The Supreme Court 1982 Term-Foreword: Nomos and Narrative, 97 HARV. L. REV. 4, 4-6 (1983).

${ }^{15}$ See Winter, Transcendental Nonsense, Metaphoric Reasoning, and the Cognitive Stakes for Law, 137 U. PA. L. REv. 1105, 1134-36 (1989).

${ }^{16}$ See N. GOODMAN, WAYS OF WORLDMAKING 2-5 (1978).

${ }^{17}$ Although habitualization of this kind must be understood as part of a process of socialization, it would be a mistake to see it solely as a matter of conscious normative instruction and deliberate rule following. See P. BERGER \& T. LUCKMANN, The Social Construction of Reality: a treatise in the sociology of KNOWLEDGE 53-55 (1967). Rather, a critical-if not more important-part of the process comes from the experience of repeated compliance itself. "Any action that is repeated frequently becomes cast into a pattern, which can then be reproduced with an economy of effort and which, ipso facto, is apprehended by its performer as that pattern." Id. at 53. In a case like that of driving, habitualization necessarily takes place in a social context that is highly structured and, so, habitualization and socialization are one and the same. See id. at 54 ("Empirically, the more important part of the habitualization of human activity is coextensive with the latter's institutionalization."). "Institutionalization" is the name that Berger and Luckmann give to this complementary process by which the individual internalizes a habit of behavior that is socially structured.

It is important to stress that this controlling character is inherent in institutionalization as such, prior to or apart from any mechanisms of sanctions specifically set up to support an institution. These mechanisms ... do, of course, exist in many institutions and in all the agglomerations of institutions that we call societies. Their controlling efficacy, however, is of a secondary or supplementary kind. As we shall see again later, the 
reverse case of a driver who stops at a red light on a deserted street at 3:00 a.m. despite the fact that the sightlines are clear, there is no cross- or oncoming traffic, and there are no police (or other witnesses) around. Why would she do so when she knows she can run the light with impunity and reach her destination more quickly? By definition, deterrence is not a factor. Yet many of us do wait for that light because we have so thoroughly internalized the rules of the road that it is almost more trouble to act against the grain than it is to wait.

We can further test the point about the role of these internal, cognitive determinants by considering the Holmesian "bad man"18 who stops at the light only because of the deterrent effect of a potential legal sanction. In that case, it appears rather obvious that the law is an external factor. Yet, even here, compliance is in an important sense an internal event for it depends upon an act of imagination. In order for deterrence to operate, our hypothetical "bad man" must be able to project the possibility of detection and the ensuing prospect of sanction. Otherwise, even the risk averse "bad man" would stop only when forced to by traffic conditions or the presence of an officer.

The gun control anecdote illustrates in another way the importance of adequate internalization and imagination to the success and coherence of the normative enterprise. Here, the requirements of the statute not only coincide with the ordinary requisites of the parental role but, in a crucial sense, depend upon the ability of particular parents effectively to fulfill that role: that is, to exercise their imaginative capacities to project a potential course of events and anticipate the possibility of danger to their children. ${ }^{19}$ Without these internal preconditions, no amount of legal legerdemain will work.

It may be objected that these anecdotes merely illustrate conventional wisdom about the limits of the legal sanction-that is, the practical limitations on enforcement that make criminalization ineffective in the face of widespread noncompliance. In the same vein, one might also question whether these anecdotes are really

primary social control is given in the existence of an institution as such.

Id. at 55 .

${ }^{18}$ See Holmes, The Path of the Law, 10 HARV. L. Rev. 457, 459 (1897).

${ }^{19} \mathrm{Cf}$. Cover, supra note 14 , at 5 (" $[\mathrm{N}]$ or can prescription, even when embodied in a legal text, escape its origin and its end in experience, in the narratives that are the trajectories plotted upon material reality by our imaginations."). 
examples of normative practice. Or, to be analytically more precise, one might draw a distinction between prescriptive and persuasive normativity. It might then be argued that the limitations which undermine attempts to prescribe norms for behavior in society, as exemplified by these anecdotes, are not applicable to efforts openly to persuade others to accept those same norms, as exemplified by the genre of legal scholarship that is the subject of this symposium.

The full argument would be rather straightforward: Because prescriptive normative practice attempts to constrain or act on the will of another, its effectiveness is limited by the will of the legal subject and her capacity to evade or resist compliance. Accordingly, the success of prescription is a function of either: (1) the favorable predisposition of the legal subject; or (2) the meaningful threat of the coercive power of the State. Persuasive normative practice, on the other hand, is by definition a noncoercive effort to engage with another to induce her willingly to arrive at and adopt a particular normative standard. In that case, all that is really needed is a clear playing field-something like a Habermasian ideal speech situation.

The ultimate aim of this essay is to demonstrate that prescriptive and persuasive normativity are necessarily dependent upon exactly the same preconditions. As a preliminary matter, however, one should consider how quickly the prescriptive/persuasive distinction collapses under examination. Every prescription, even "No Turn on Red," has a hortatory character; indeed, for the person who has internalized an ethic of compliance with legal directives, it is an exhortation entirely sufficient to persuade that person to behave in a certain manner regardless of the advantages of noncompliance (like getting home more quickly). For the driver who runs the light and disobeys the sign, its injunction is as much an effort at persuasion as prescription. Indeed, the more cavalier the driver, the more blithely the driver disregards the relevant traffic laws, the more it will be the case that the sign can be understood only as a last ditch attempt at persuasion. How else can we interpret the "No Turn on Red" sign in the opening anecdote?

In the gun control anecdote, prescription is transmuted into persuasion in two different ways. First, the statute can be understood as emphasizing the gravity of the problem and, thus, as an exhortation to parents to take greater care. Second, and perhaps more importantly, the statute spells out for the thoughtless the predictable relationship between the negligent storage of handguns and the risk of ensuing accidents. In making this connection public, the statute takes the place of the deficient imaginative capacities of 
those parents who do not otherwise anticipate the possibility of danger to their children. But, for those parents who care about their children, the work of persuasion is already accomplished once the statute supplies that link.

The distinction between prescriptive and persuasive normativity is no more stable when examined from the other side. Persuasive normativity cannot be understood apart from its prescriptive dimensions; in an important sense, every act of persuasion has its origin and end in prescription. This is self-evidently true of normative legal scholarship. At the outset, it must take certain forms if it is to be recognized as legal rather than purely political and as scholarship rather than mere advocacy. Its yield, moreover, is explicitly prescriptive. The very point is to persuade the reader that a particular prescription should be adopted-whether it be the author's proposed three-part test, theory of interpretation, or recommended approach to legal theory.

But this dependence upon prescription is no less real for the more ambitious, democratic versions of persuasive normativity. Every effort at normative persuasion, by necessary implication, presupposes that there is divergence amongst the initial normative positions. Except in the rarefied realm of pure theory, even the most utopian normative aspirations must take into account the possibility of imperfect agreement. It follows, therefore, that persuasive normativity is utterly dependent upon prescription. For, in the face of imperfect agreement, all efforts at persuasion must conclude in prescription. Moreover, if those prescriptions are to derive their legitimacy from the persuasive (rather than coercive) nature of the decisionmaking process, then that process must itself be premised on some prescription that specifies in advance the conditions under which dialogue will count as persuasion rather than coercion. ${ }^{20}$

This deconstruction of the distinction between prescription and persuasion is more than a clever rhetorical ploy. It sets the stage for my argument that all forms of normativity-both prescriptive and persuasive-are unavoidably contingent on community. But it does

${ }^{20}$ Of course, this prescription itself may be the product of deliberation; there is no necessary logical or temporal sequence to this process of prescription/persuasion. But, if there is less than perfect agreement during the deliberative part of the process, there necessarily will be a purely prescriptive dimension to the ensuing ground rules. Only unanimity can save persuasive normativity from infinite regress; even then, one subsequent dissenter will destroy the consensual dimension of the process. 
more than that, for the last point, concerning the prescriptive procedural conditions for persuasion, also encapsulates the argument in its broadest form. Consider, for example, Frank Michelman's candid description of the necessary preconditions for the form of normative persuasion he calls "republican jurisgenesis":

Given plurality, a political process can validate a societal norm as self-given law only if (i) participation in the process results in some shift or adjustment in relevant understandings on the parts of some (or all) participants, and (ii) there exists a set of prescriptive social and procedural conditions such that one's undergoing, under those conditions, such a dialogic modulation of one's understandings is not considered or experienced as coercive, or invasive, or otherwise a violation of one's identity or freedom $\ldots$. $^{21}$

On the first reading, statement (ii) is an explicit acknowledgement that republican persuasion is dependent on the existence of prescriptive preconditions. But a closer reading of the passage indicates that persuasion entails "community" in the very sense that I have employed it. For it is only within a community of shared understandings that one could experience as noncoercive, noninvasive, and respectful of one's freedom, a process in which one is the object of dialogic modulation by others. ${ }^{22}$ It is only when all the participants have internalized the same set of prescriptions as constituting a dialogue (and not, say, a diatribe or harangue) that undergoing dialogic modulation by others would be experienced as persuasion and not prescription.

But there is more to my argument, to which we now turn.

\section{LOCATING CoMmUNITY IN THE SELF}

In one sense, the argument so far may seem exactly backward. Ordinarily, law (i.e., normative prescription) is understood to comprehend the coercive threat of state violence. What distinguishes the claim of dialogue (i.e., normative persuasion) is that it offers a legitimate, noncoercive means for achieving social order. In other words, prescription (law in a strong sense) is what we rely on when there is no community. The aspiration of persuasive normativity, on the other hand, is to establish a community-indeed one that is

${ }^{21}$ Michelman, Law's Republic, 97 YALE L.J. 1493, 1526-27 (1988).

22 In Michelman's words, it is a process of "one's undergoing, under those conditions, such a dialogic modulation of one's understandings ...." Id. at 1527. 
free and self-governing. Yet, paradoxically, I have claimed that community is a prerequisite to the success of prescription and, tautologically, that community is a necessary precondition even for the effort to establish community through dialogue.

It might seem that I have created this conundrum by adopting an idiosyncratic definition of community. But I don't think so, as I try to show below. In the subsections that follow, I examine a recent argument that opposes the coercive nature of law to the very concept of community. I then show that the conception of the self upon which this concept of community is based cannot accommodate a wide range of the social phenomena it purports to describe. In the final subsection, I expand upon those phenomena to provide a more meaningful account that locates community in the processes of the self.

\section{A. Community and the Concept of Role}

In an essay entitled Law, Community, and Communication, Meir Dan-Cohen argues that law is better understood as a form of strategic communication issuing from the bureaucratic organization known as the State. ${ }^{23} \mathrm{He}$ explicitly contrasts this vision of law with Ronald Dworkin's idea of law as interpretation which, he suggests, is closely related to Habermas's distinction between "communicative action" and "strategic communication": "In communicative action, the participants are oriented toward reaching agreement through understanding. In strategic communication, by contrast, participants are oriented toward success; they have a specific goal determined antecedently to their discursive behavior that the latter is designed to promote. ${ }^{n 4}$ Like communicative action, Dworkin's "interpretation takes place in the context of community" under ideal conditions that "secure a degree of cognitive alignment and

${ }^{23}$ See Dan-Cohen, Law, Community, and Communication, 1989 DukE L.J. 1654, 1669-71. Professor Dan-Cohen acknowledges that there are aspects of the State and of legal interpretation that correspond to notions of community, but stresses that "short of utopia, we must contend with both poles." Id. at 1676. His emphasis on strategic communication and bureaucratic organization "is purely reactive, to right an imbalance in present day jurisprudence that Dworkin's theory mainly creates." Id. at 1675. Because I am much less interested in his account of adjudication than in his concept of community, I consider the argument at face value even though it is explicitly offered as only a partial account. But, by the close of this essay, it should be clear why the distinction between communicative action and strategic communication-and the identification of adjudication with the latter-cannot be maintained.

${ }^{24}$ Id. at 1660 . 
motivational coordination among the participants ..." ${ }^{25}$ The Dworkinian judge in effect engages in a dialogue with his predecessors, and this dialogue presumes that the participants share the ambition to be a community of principle whose decisions can be rendered coherent in terms of "the consistency of principle [that] integrity requires. ${ }^{26}$

In contrast, Dan-Cohen claims that legal argument and judicial decisionmaking more strongly resemble strategic communication than communitarian efforts at reaching agreement through understanding. The fulcrum of his argument is the concept of roledistance, which he borrows from the sociologist Erving Goffman. ${ }^{4}[\mathrm{~T}]$ he concept of role-distance . . . relates to the self's capacity to locate itself, metaphorically speaking, at variable distances from the different roles it occupies. ${ }^{27}$

Some roles are relatively central to and even identified with one's sense of self. These are non-detached roles which the self enacts "transparently" in the sense that its "will is identical (within the role's domain) with the role's requirements. There is therefore no question of providing . . . [it] with some 'external' motivation to perform the various aspects of ... [the] role ...." ${ }^{28}$ There are other roles, however, in which the self experiences substantial roledistance. These detached roles are characterized by self-consciousness in their performance, the awareness that the self is play-acting or just conforming to social requirements and expectations. ${ }^{29}$ As

${ }^{25}$ Id. at 1661 .

${ }^{26}$ R. DWORKIN, LAW's EMPIRE 228 (1986). Dworkin continues:

Law as integrity asks judges to assume, so far as this is possible, that law is structured by a coherent set of principles about justice and fairness and procedural due process, and it asks them to enforce these in the fresh cases that come before them .... That style of adjudication respects the ambition integrity assumes, the ambition to be a community of principle.

Id. at 243.

27 Dan-Cohen, supra note 23, at 1654-55 (discussing E. GOFFMAN, Role Distance, in ENCOUNTERS: TWO STUDIES IN THE SOCIOLOGY OF INTERACTION 85 (1961)).

${ }^{28} I d$. at $1656-57$.

29 See id. at 1655; see also Gabel, The Phenomenology of Rights-Consciousness and the Pact of the Withdrawn Selves, 62 TEX. L. REV. 1563, 1569 (1984) ("[S]he and I both know, whether consciously or not, that she is not being herself but rather an ineffable 'someone else'-a 'bank teller.' ... [T] The as-if performances . . . are makeshift phantoms that lack any ground, straining in 'mid-air,' you might say, to deny the other access to the withdrawn someone who we really are."). Dan-Cohen recognizes, however, that degrees of detachment are not inherent properties of roles and that, for a given role, role-distance can fluctuate over time. See Dan-Cohen, supra note 23, at 1655 . 
a consequence, the requirements of detached roles do not become the self's own. Detached roles, therefore, present "starkly the problems of motivation, autonomy, and coercion. ${ }^{\text {30 }}$

Dan-Cohen uses this concept of role-distance to distinguish between two forms of social affiliation and their attendant modes of communication. A community, the paradigm for which is the ideal family, is a collectivity of non-detached roles. A bureaucratic organization, exemplified by a large corporation like AT\&T, is a social union of detached roles that allow or even call for distance. ${ }^{31}$ Each of these forms of association is in turn identified with a particular mode of communication. Because a community is constituted by the intersection of non-detached roles, the resulting "cognitive alignment and motivational coordination" ${ }^{\text {"2 }}$ allows for interpretation, persuasion, and potential agreement through understanding. On the other hand, because a bureaucratic organization is essentially a loose association of detached roles, the resulting distance and motivational dissonance will require strategic communication oriented toward achieving the organization's preexisting goals.

The primacy of strategic forms of communication within organizations is related to the fact that bureaucratic rationality is preeminently instrumentalist rationality.

[T] he organization is characteristically engaged in a competitive struggle for scarce resources to put to the service of its predetermined ends. It is therefore a central responsibility of managers to direct and redirect their organizations' available resources, both human and non-human, as effectively as possible toward those ends. ... Bureaucratic rationality is the rationality of matching means to ends economically and efficiently. ${ }^{33}$

Thus, Dan-Cohen suggests that the role-distance which characterizes a bureaucracy may be peculiarly adapted to facilitate its strategic goals. On one hand, it aicls the organization: Detached roles can be more efficiently managed, interchanged and, if necessary, eliminated. On the other hand, role-distance protects the individual: " $[B] y$ isolating the self from the organizational role, role-

${ }^{30}$ Dan-Cohen, supra note 23, at 1657.

31 See id. at 1659.

32 Id. at 1661.

33 A. MACINTYRE, AFTER VIRTUE: A STUDY IN MORAL THEORY 25 (2d ed. 1984). 
distance shields the self to a degree from the blatant instrumentalism of these organizations." 34

With this analytic framework in place, Dan-Cohen assesses the nature of adjudication. Legal discourse, he explains, is primarily strategic. The legal arguments and courtroom tactics of the advocate are designed not so much to achieve agreement through understanding as they are oriented strategically to achieve success for the client. Accordingly, the role of the advocate is best understood in terms of role-distance. "Lawyers routinely say, and indeed are expected to say, things they are not supposed to believe." ${ }^{35}$ In this mode, the advocate operates as part of an organization-a municipal legal system under the auspices of the State-that consists in the interaction of these detached roles. ${ }^{36}$

Much the same is true if one considers adjudication from the perspective of the judge. Her opinions are designed strategically "to secure compliance, not to generate agreement ...."37 Although the judicial opinion can be characterized as an effort to persuade the parties to comply, it also serves as the prescriptive warrant for an enforcement bureaucracy. ${ }^{38}$ Thus, the judicial role must be a detached one, for the judge too will need to be shielded from the blatant instrumentalism of her role. ${ }^{39}$ It follows from this conclusion that the institution of adjudication is basically a bureaucratic rather than communal form. "It is an avowed purpose of this social structure to secure order and promote cooperation, if need be by force, in the face of recalcitrance, moral diversity, and disagreement." 40

34 Dan-Cohen, supra note 23, at 1659.

${ }^{35} I d$. at 1666.

${ }^{36}$ See id. at 1669.

${ }^{37} \mathrm{Id}$. at 1672 .

${ }^{38}$ See id. at 1673 ("Judicial utterances are supposed to secure certain forms of conduct .... These utterances are therefore success-rather than truth-oriented ...." $)$.

${ }^{39}$ The theory of cognitive dissonance, however, would suggest that just the opposite will be the case: The more blatantly instrumental the judge's role, the more she needs to be shielded from the implications of what she does, the more likely it is that the judge will be convinced that her actions and conclusions are necessary and objective. In other words, the more coercive and distasteful the role, the greater will be the need to achieve a cognitive alignment between the demands of the role and a flattering conception of "self." Cf. Altman, Beyond Candor, 89 MICH. L. REV. 296, 325 (1990) ("Taking moral responsibility for deciding indeterminate cases is unpleasant, giving judges a reason not to notice how often they make rather than follow law."); id. at 329-30 (noting that "they need to maintain their self-esteem, which is dependent on internalized norms that are in part socially created").

10 Dan-Cohen, supra note 23, at 1675 (citing Cover, supra note 14; Cover, Violence 
As I have rehearsed the argument so far, it is a sophisticated account of the conventional understanding that opposes the coercive prescription of law to the community-building of persuasive normativity. ${ }^{41}$ It provides, moreover, a fully articulated, theoretical conception of community that is antithetical to the claim that both forms of normativity are contingent upon community. Thus, the argument would seem to substantiate the suggestion made above that this supposed contingency is the product of an unusual and mistaken definition of community. It does not, however, and the reason is twofold: First, Dan-Cohen's theoretical conception of community cannot be sustained; and, second, its shortcomings lead directly to a conception of community as, first and foremost, a cognitive phenomenon.

\section{B. A Role, By Any Other Name...}

The problem with Dan-Cohen's account inheres in his central conception-the idea of role-distance. Early in his essay, Dan-Cohen provides two illustrations that are explicitly intended to obtain the reader's assent to his concept of role-distance. First, he asks the reader to consider the role of parent. "Since there is no distance between me and my role as a father, since I fully identify with that role, the imperatives that guide me in discharging it are in an important sense internal to me. ${ }^{n 2}$ As a consequence, the father needs no "external' motivation to perform the various aspects of my parental role-for example, to get up to my crying baby-since an 'internal' motivation is already provided in the assumption that I enact parenthood as a non-detached role. ${ }^{n 3}$ When a person is acting within the domain of a non-detached role, coercive prescription is entirely out of place. Rather, it becomes necessary only "when a gap has been opened between the person and his or her role as parent ...."44

and the Word, 95 YALE L.J. 1601 (1.986)).

${ }^{41}$ If the argument falls short, it would seem to be a consequence of the selfconscious choice to emphasize one half of an admittedly more complex dynamic. See Dan-Cohen, supra note 23, at 1665-75. For a discussion of how the coercive, communal, and transformative dimensions of law are all entailed in our basic conception of law and legal rights, see Winter, supra note 15, at 1207-34.

42 Dan-Cohen, supra note 23, at 1656.

43 Id. at 1657. Note that the terms "internal" and "external" are in quotes. I shall return to the significance of these quotes in the discussion below. See infra text accompanying notes 61-67.

44 Dan-Cohen, supra note 23, at 1657. 
To this idyllic picture of parenthood, Dan-Cohen juxtaposes the organizational role of a telephone operator at AT\&T. All that is required of the operator is that he or she go through the motions of the role with adequate proficiency. As an operator, one is entirely free to

keep the role at a distance-outside of me-the role's requirements do not, in and of themselves, become my reasons or motivations for complying with them. The various tasks that compose the telephone operator's role, such as answering the numerous phone calls and operating the electronic switchboard, are not the things the operator himself has any reason or desire to do. (The crucial point here is that it makes perfectly good sense to refer to the operator himself, meaning the operator qua person, aside from this particular role. By contrast, it ordinarily would be clumsy to separate a person from, say, the parent that he is. $)^{45}$

Thus, an AT\&T operator enacts a detached role that is part of a bureaucratic organization. "For this reason, he in principle must be bribed or coerced if he is to perform the role's requirements. ${ }^{\text {}} 6$

This demonstration has more than surface plausibility. Nevertheless, it is already in trouble before the first illustration is completed, for it presupposes an entire set of assumptions that will not stand a minute's scrutiny.

Dan-Cohen wants to persuade us to accept not only his distinction between detached and non-detached roles, but also his further point that coercion and strategic communication (i.e., the prescriptive side of normative practice) are appropriate only when a person enacts a detached role or suffers from alienation and enacts a non-detached role in a detached manner. ${ }^{47}$ His primary illustration is the parental role, where coercion is beside the point because the motivation properly to perform the role is already internal.

But one should consider again all those parents in Florida who left loaded handguns where their children might find them. It is clear that these parents were in dire need of some motivational supplement if they were properly to perform their roles as parents. Yet it does not seem likely that, in each and every case, these parents were suffering alienation from their parental role. Quite

${ }^{45} \mathrm{Id}$.

${ }^{46} \mathrm{Id}$. at 1658.

${ }^{47}$ For Dan-Cohen, "alienation is an inappropriate role-distance-i.e., it is distance from what is supposed to be one's communal role." Id. at 1659. 
the contrary, it is safe to assume that some (if not most) of these parents were every bit as devoted to their children as you or I might be. Indeed, it is likely that many of these parents actually purchased guns as an entirely genuine exercise of their non-detached parental roles-that is, a felt responsibility to protect their families and homes. ${ }^{48}$

Dan-Cohen's parental role illustration seems to make his point only because he has chosen an example that is calculated to resonate with the particular audience whose assent he is trying to obtain. Since this audience consists of educated, middle class readers thoroughly acculturated to mainstream values-people like you and me-he is quite safe in presuming that we will share a common set of assumptions about the details of the parental role and what is required when the baby cries. Thus, when he asserts that the parent's motivation for soothing the baby "is already provided in the assumption that I enact parenthood as a non-detached role, ${ }^{n 49}$ he is in fact correcr: We do already share the same set of assumptions about the parental role, its importance, and its authenticity in our lives; he has only to invoke it and name it. Like every instance of persuasive normativity, this argument works because it takes place within a community consisting of those who already share a particular way of understanding and living in the social world.

We can further test the point by considering Dan-Cohen's parental illustration in light of two counterexamples: one in the context of persuasive normative practice and the other in the context of prescription. You will note that Dan-Cohen has the father, as a self-motivated performance of his parental role, getting up in the middle of the night to soothe the crying baby. Now imagine a normative dialogue in which you are trying to persuade a different father that he should do the same. Only this father is your grandfather or a contemporary father who is part of a still rigidly patriarchal culture in another part of the world-let's say

48 I argued above that, as a means for motivating parents properly to perform their parental role, this is a very silly statute. See supra text accompanying note 12. But it is not silly for the reason suggested by Dan-Cohen. In his analytic scheme, parenthood is a non-detached role and, as such, is one for which coercion and other forms of "external" motivation are simply out of place. It would follow from this reasoning that, since driving a car is a relatively detached role, coercive prescription should be entirely appropriate in that context. Yet, if anything, the "No Turn on

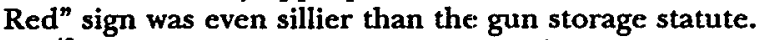

19 Dan-Cohen, supra note 23, at 1657 (emphasis added). 
Saudi Arabia. The first thing we notice about this situation is that the claim that a father who is non-detached from his parental role will have an "internal motivation" to get up to soothe his crying baby has suddenly become false: It's a safe bet both that your grandmother was the one to get up when your mom or dad cried and that the Sheik never does. Moreover, the cultural contingency of these gender-based parental roles has tremendously complicated your task of persuasion. If you say to granddad or the Sheik "Now it's your job as father to get up and soothe that baby," you are likely to get that look of incomprehension that also says "this person is crazy." And if you try to engage him with arguments of fairness and equality, he is likely to point out: (1) that he is the breadwinner and sole supporter of the family and needs his sleep; (2) that babies respond better to maternal comfort and, after all, mothers are better at nurturance; or (3) that it would be unmanly and would subject him to dishonor.

When all efforts at persuasion had failed, you might then be tempted to fall back on prescription. But note that this prescriptive effort would be the consequence of the fact that these fathers refuse to enact anything but their non-detached roles (as they understand them). Consider, moreover, another kind of parent, the kind who responds to the crying baby with anger, frustration, and physical abuse. Here, we might all agree, is a classic case for coercive prescription: Notwithstanding our best efforts at corrective persuasion, there is a helpless infant that must be protected. But if some measure of coercion makes sense in this context, it is not because "a gap has been opened between the person and his or her role as parent. ${ }^{\text {50 }}$ The abusive parent is not acting out a detached role. Rather, this person does not share-and, therefore, does not have the capacity to enact-our conception of the parental role. ${ }^{51}$

${ }^{50} \mathrm{Id}$.

51 For a psychoanalytic explanation of this phenomenon, see A. MILLER, THOU SHALT NOT BE AWARE: SOCIETY's BETRAYAL OF THE CHILD (1984):

The consequences of sexual abuse, however, are not restricted to problems in one's sexual life; they impair the development of the self and of an autonomous personality. There are several reasons why this is so: . . .

[T] he fact of abuse must be repressed for the sake of survival. . . . The consequences of a trauma are not eliminated by repressing it but are actually reinforced. The inability to remember the trauma, to articulate it ... creates the need to articulate it in the repetition compulsion.

The unremembered plight of being at someone else's mercy and being abused by a loved object is perpetuated either in a passive or active role, or alternatively in each. ... 
The tragedy of child abuse is that so many abusive parents were themselves products of abusive families. ${ }^{52}$ The problem is not that the abusive parent is detached from the parental role, but rather that he or she may be all too much attached to a twisted version of that role.

The example of the AT\&T operator as enacting a detached role in a bureaucratic organization seems to work better, but only because it too is chosen to fit. In fact, Dan-Cohen acknowledges immediately that a bureaucratic organization may contain upper echelon management positions that are enacted as non-detached roles. He recognizes that this would make AT\&T a hybrid entity (a bureaucratic community, perhaps?), but deflects the point by observing that: "Putting aside the historical question of how AT\&T came to be, the organization presently can consist entirely of detached roles ...." ${ }^{\text {53 }}$ The fact that it happens to have some nondetached roles is for Dan-Cohen a conceptual accident, an unnecessary condition that can nevertheless be accommodated within the organization. ${ }^{54}$

The point, however, cannot be deflected because Dan-Cohen's basic premise is in trouble both as a descriptive and conceptual matter. It is in trouble as a descriptive matter because we know that the CEO of AT\&T not only eats, sleeps, and breathes his role, but also that this is how he got to be CEO. We are all familiar with the concept of "a team player," "the company man," or "the man in the grey flannel suit." No one rises in a bureaucracy unless she makes it her own (and, simultaneously, it makes her its own). The efficient manager is one who can direct the organization's human resources with total commitment and single-mindedness, free of the compro-

One of the simplest and completely unnoticed forms of perpetuation of the active role is abuse of one's children for one's own needs, which are all the more urgent and uncontrollable the more deeply repressed the original trauma.

Id. at 162-63.

52 See M. Straus, R. Gelles \& S. Steinmetz, Behind Closed DoORs: VIolence IN THE AMERICAN FAMILY 97-122 (1980); id. at 121 ("We traced this learning process through three generations. The more violent the grandparents, the more violent the couples in our study are as husbands and wives, and the more abusive they are to their children."). It is important, however, to recognize that there is only a correlation between experience in one's family of origin and abusive behavior as an adult and not a direct and invariant causal relationship. See id. at 122.

53 Dan-Cohen, supra note 23, at 1658.

${ }^{54} \mathrm{See}$ id. ("Although it is not required that some of AT\&T's roles be nondetached, however, there would be no contradiction in terms of my proposed scheme if, in fact, some role were to be enacted so."). 
mise, doubt, and cynicism that infect the enactment of a detached role. ${ }^{55}$ To the observation that "[b]ureaucratic rationality is the rationality of matching means to ends economically and efficiently, ${ }^{\text {56 }}$ one might add "and do so without guilt."

It is in trouble as a conceptual matter because, far from an accidental element of a corporate bureaucracy, the non-detached role of manager may be a quintessential element of modern culture. That, at least, is Alasdair MacIntyre's claim. In contrast to DanCohen's distinction between detached and non-detached roles, MacIntyre introduces a distinction between a social role and a "character"-for which his contemporary paradigm is the bureaucratic manager. ${ }^{57}$ What makes a character distinct from an ordinary role is the way in which it functions as a central reference point and determinant both for the person and the society:

There is a type of dramatic tradition-Japanese Noh plays and English medieval morality plays are examples-which possess a set of stock characters immediately recognizable to the audience. Such characters partially define the possibilities of plot and action. To understand them is to be provided with a means of interpreting the behavior of the actors who play them, just because a similar understanding informs the intentions of the actors themselves; and other actors may define their parts with special reference to these central characters. So it is also with certain kinds of social role specific to certain particular cultures. They furnish recognizable characters and the ability to recognize them is socially crucial because a knowledge of the character provides an interpretation of the actions of those individuals who have assumed the character. It does so precisely because those individuals have used the very same knowledge to guide and to structure their behavior. ${ }^{58}$

${ }^{55}$ For those of you who are viewers of the $\mathrm{ABC}$ television show thirtysomething, this is what Miles Drentell is forever trying to impress upon Michael Steadman.

${ }^{36}$ A. MACINTYRE, supra note 33 , at 25.

${ }^{57}$ See id. at 27-28. MacIntyre also notes:

Characters ... must not be confused with social roles in general. For they are a very special type of social role which places a certain kind of moral constraint on the personality of those who inhabit them in a way in which many other social roles do not. . . . Many modern occupational roles-that of a dentist or that of a garbage collector, for example-are not characters in the way that of the bureaucratic manager is .... In the case of a character[,] role and personality fuse in a more specific way than in general ....

Id.

${ }^{58} I d$. at 27. 
It is the centrality and culturally shared nature of the character of the bureaucratic manager that makes plausible both Calvin Coolidge's claim that "The business of America is business" and the part of Miles Drentell on the ABC television show thirtysomething. ${ }^{59}$

I am not so much interested whether MacIntyre or Dan-Cohen provides the better conceptual distinction. Indeed, I have similar problems with both sets of distinctions precisely because they are distinctions and, therefore, spatialize what is better understood as a cognitive process. But I am intrigued by the fact that they both choose the domain of bureaucratic organization and management to exemplify their very different conceptions: Where, for DanCohen, a bureaucratic organization is defined by its detached roles, for MacIntyre it is an institution that is definitional for its constituents and for society at large. Yet, each account seems to be true at least in part. What this suggests is that there may be better ways to understand the complexities of such intrapsychic phenomena.

Consider again the case of the telephone operator. True, this is ordinarily not the kind of role upon which one builds a personal identity. But it is not inconceivable. The comedienne Lili Tomlin rose to fame in part on her characterization of Ernestine, the telephone operator who is only too happy to let the customer know that "we" won't put up with that, "we don't have to, we're the phone company." Ernestine is not detached from her bureaucratic role; if anything, she takes her role too seriously. Ernestine is of course fiction, but the character works precisely because the audience recognizes in her the overweening petty bureaucrat who, in real life, does power-trip in just this way.

Dan-Cohen does have a normative response to this phenomenon: He identifies it as a "disease" that, following Sartre, he calls bad faith-that is, "misplaced identification with what ought to be a distanced, organizational role." 60 But surely this is too harsh. Normally, we consider ourselves fortunate when we encounter secretaries or other support staff who identify with their roles and who pride themselves on their capacity to perform those roles with efficiency and dispatch. The greater the identification, the more they are self-motivated, the more fortunate we consider ourselves.

${ }^{59}$ See supra note 55. (1943)).

${ }^{60}$ Dan-Cohen, supra note 23, at 1659 (citing J.P. SARTRE, L'ETRE ET LE NEANT 82 
Far from condemning these people for bad faith, we applaud them for their sense of professionalism.

In sum, Dan-Cohen's concept of role-distance does not do the work he requires of it because it cannot accommodate a wide range of the social phenomena it purports to describe. The reason for this is simple: The unarticulated premise upon which it is based is a deeply flawed conception of the "self."

\section{Separation Anxiety}

The problems with Dan-Cohen's concept of role-distance have everything to do with the way in which he spatializes it. Roledistance "relates to the self's capacity to locate itself, metaphorically speaking, at variable distances from the different roles that it occupies." 61 "The distance between a person and a role can shrink or expand." 62 "[A] gap has been opened between the person and his or her role as parent." 63 By necessary implication, this way of spatializing the self and its roles entails a conception of the self as separate from those roles. True, some roles are (to use DanCohen's phrase) worn more tightly than others. ${ }^{64}$ But this metaphor too separates the "true" self from its temporary garb. The concept of a role, moreover, is reified and treated as an object "out there." This separation of the self from its roles is what leads DanCohen to define alienation and bad faith in the way that he does. Alienation is when the self does not recognize that the role which it is holding at arm's length should "really" be congruent with its "true" self. Bad faith is when a role that should be maintained at arm's length is instead misidentified as one's "own" self.

But if the self is separated from its roles in this way, then for Dan-Cohen it must necessarily be empty of social substance. And, indeed, it is: When this self fully "occupies" a role-that is, when it assumes a role in a non-detached way-the self becomes coextensive with that role and takes on its content. No "external" motivation is then necessary because the motivation has been assumed along with the non-detached role and, thus, has become "internal" to the self. $^{65}$ Conversely, when this empty self is detached from a role-

61 Id. at 1655 (emphasis added).

${ }^{62} I d$. (emphasis added).

${ }^{63} I d$. at 1657 (emphasis added).

64 See id. at 1655 ("It is also not the case that some roles must be worn tightly, whereas others are kept at a distance by all their takers.").

${ }^{65}$ See id. at 1657 (quoted supra text accompanying note 43). 
that is, when there is a "gap" between the self and the role-the motivation of the role remains foreign to the self. "Insofar as the role that I enact is a detached one, I experience the role's imperatives as external ...."66 Motivation becomes a "stark problem" because the self has no neciessary reason to comply with the role's requirements. ${ }^{67}$

If, for Dan-Cohen, the self is substantively empty in this way, it must nevertheless contain a residuum of pure will that is separate from any motivationally complex role that it might assume. ${ }^{68}$ And this is exactly how he does conceive it, for it is only if the self has a will separate from its roles that he could refer to "the self's capacity to locate itself" with respect to a particular role. ${ }^{69}$ And this, in turn, implies radical freedom: "The democratized self which has no necessary social content and no necessary social identity can then be anything, can assurne any role or take any point of view, because it is in and for itself nothing. ${ }^{70}$ It is, moreover, this conception of a radically autonomous self that unites the otherwise disparate views of Goffman and Sartre which Dan-Cohen has partially conjoined:

In Goffman's anecdotal descriptions of the social world there is still discernable that ghostly 'I', the psychological peg to whom Goffman denies substantial selfhood, flitting evanescently from one solidly role-structured situation to another; and for Sartre the self's self-discovery is characterized as the discovery that the self is 'nothing', is not a substance but a set of perpetually open possibilities. Thus at a deep level a certain agreement underlies Sartre's and Goffman's surface disagreements; and they agree in nothing more than this, that both see the self as entirely set over against the social world. ${ }^{71}$

Dan-Cohen replicates the radical autonomy of the self in his theoretical account of community.

When individuals ... efface all distance between themselves and their communal roles, then the system of interlocking roles, which

${ }^{66} \mathrm{Id}$.

${ }^{67}$ See id. at 1657 ("[T] he role's requirements may coincide, of course, in general or in any specific instance with my wants and desires. But this coincidence is, in principle, adventitious ....").

${ }^{68}$ What distinguishes a role as non-detached is only that the self's "will is identical (within the role's domain) with the role's requirements." Id. at 1656 (emphasis added).

${ }^{69} \mathrm{Id}$. at 1655.

${ }^{70}$ A. MACINTYRE, supra note 33 , at 32.

${ }^{71}$ Id. 
is the community, constitutes a configuration of partially intermingled personal identities. "Partially," because the individual identities intermingle only along the dimension or within the domain that defines and bounds the particular community that these individuals share. But insofar as matters concerning the community go, the members occupy a common space ....72

The imagery here is stark. There are independent selves in their closely held, non-detached roles. These individuals are not themselves connected, only the roles they hold are attached to one another. The attachments between the roles will constitute the individuals as a group bound together "only along the dimension or within the domain" of these role-attachments. The community is nothing but the social space marked out by the relations between these non-detached roles. The individuals "themselves," however, always remain outside the group just as they always remain separate from their roles.

To be clear just how extreme is this separation between the self, on one hand, and even its non-detached roles and communities, on the other, consider the following example from the very next section of Dan-Cohen's essay:

Suppose that someone had just helped my four year-old daughter to cross the street, as I happen to walk by. ... [S]o I say to this benefactor something like, "Thank you for helping my daughter." The first thing to notice about this situation is this: My expression of gratitude is strictly a matter of performing my role as father. After all, the benefactor has not rendered any help directly to $m e$. It is only by virtue of my parental role, and as an aspect of it, that it is appropriate and necessary that $I$ thank the helper under these circumstances. ${ }^{73}$

Although I shall have more to say about this passage in the next section, think about how estranged this self really is from its role as father: Providing assistance to his daughter is no benefit to him, as if her well-being were not integral to his happiness. This father expresses gratitude only because it is dictated by his role and by his self-identification as a polite person. "In this case, my general tendency to be a polite person is sufficient to secure my performance of such a speech act, because my being a father is simply the aspect of my personal identity that pertains to the situation at hand." 74

72 Dan-Cohen, supra note 23, at 1661 .

73 Id. at 1662.

${ }^{74}$ Id. (emphasis added). 
This is a desiccated view of the self. It is a self that keeps even its most important non-detached roles at a distance. It leads, moreover, to a complementary view of community that is unrealistically saturated. Where the individual self is always empty of social content, the community is all social content. This vacuum of a self has room for an autonomous will; it can don its roles or hold them at a distance and, by this choice, participate in community. The community, in contrast, is too full of tightly integrated social relations between non-detached roles to contain any actual selves capable of deviance.

If these conceptions of the self and its communities are unrealistic, they nevertheless complement one another perfectly. When this empty, individual self occupies one of its non-detached roles, it becomes coextensive with that role-space and, by that fact alone, tightly integrated into the community. ${ }^{75} \mathrm{But}$, although it is not the least bit surprising, this leads Dan-Cohen to the peculiar and faulty conclusion that a community is a monolithic system that is as unified and well integrated as a single individual might be. Thus, in the sentence that immediately follows the passage describing the members of a community as occupying "a common space," DanCohen concludes: "We plausibly can imagine their public discourse as taking place within a single member's private forum precisely because the relevant zone of that private forum is continuous with the community's public space." 76

Now it seems to me that every part of this picture is wrong. Public discourse is not at all like an internal monologue; even within a community of interlockings non-detached roles, the individual member's role-space is not identical to, but only "continuous with the community's public space. ${ }^{777}$ At the same time, the self is not at all like an empty vessel temporarily filled up by (and then emptied of) a succession of different non-detached roles. In the real world, a self has many different non-detached roles-and, therefore, many different communities-which must coexist. If we are to spatialize the self, then it must be sectorized. ${ }^{78}$ If that is so, then we should expect the self to experience competition between the demands of

${ }^{75}$ See, e.g., id. (" $[O]$ nce I have ascertained that it is incumbent upon a father to express gratitude under these circumstances, no further question about motivationi.e., why did $I$ express gratitude-arises.").

${ }^{76}$ Id. at 1661-62.

${ }^{77} I d$. at 1662 (emphasis added).

78 This is suggested by Dan-Cohen's reference to the "relevant zone of th[e] private forum" of the self. Id. 
its different non-detached roles. And, on occasion, this would require the self to choose between and deviate from one of its communities.

This phenomenon of role-competition presents two serious problems for Dan-Cohen. First, there is the question of how an empty, autonomous self chooses among its closely held, but potentially incommensurate non-detached roles. Second, it would no longer be meaningful to say that community is a "common space" and public discourse is like an internal monologue. Rather, any community of interlocking non-detached roles would have to contend with real world sectorized-selves who respond to the pull of different roles (and their corresponding communities). These riven selves would inevitably introduce fissures into any community, which is another way of saying that there is an unavoidable plurality that characterizes real world communities.

Dan-Cohen's theoretical account of autonomous selves who participate in communities of neatly interlocking non-detached roles is just that-a purely theoretical account. We can begin to improve upon it by reconsidering the concepts of self, role, and community in light of the kinds of social phenomena we have explored. We will find that-in a crucial sense-self, role, and community form a single, indivisible, ecological system. The self cannot be understood apart from its relation to its roles and other learned modes of interaction; those roles are modes of interaction with others that cannot be understood separate from the community of those with whom the self interacts; and, finally, the community cannot be detached from the way in which it is reproduced in and by the self.

Consider first the concept of the empty self that dons its nondetached roles and through them participates in community. Where does this self come from? Every actual self begins as part of a community that it does not choose and cannot escape, unless perhaps when it is removed from one community and placed in another. "No human infant could survive without the nurturance of other people; its earliest experiences already provide it with an entire repertoire of psychological mechanisms, defenses, complexes, and personality traits." ${ }^{79}$ Thus, by the time it is old enough to leave its family, the self is in many ways already formed. The experience of having been parented, for example, provides a model

79 Winter, Indeterminacy and Incommensurability in Constitutional Law, 78 CALrF. L. REv. 1441, 1486-87 (1990) (footnote omitted). 
or base from which one's future actions in similar circumstances take form. ${ }^{80}$ In this way, one learns the behaviors that are typical and appropriate for various contexts. ${ }^{81}$ "What this means is that, because the subject is fashioned in its interaction with its physical and social world, it always already contains those relationships within it as the imaginative abstractions of those interactions. ${ }^{n 82}$ The end product is a distinctive kind of self that behaves in a characteristic way. ${ }^{83}$

Consider again the relationship between the self and the parental role. One can "choose" whether to become a parent, but the conception of the parental role that informs this "choice" has already formed and become the self. ${ }^{84}$ Once that choice is made, the performance of that role will largely reflect the internal model by which this self knows what it means to be a parent. Thus, if one's "autonomous will" to get up to soothe one's crying child is identical with the requirements of the parental role, it is because the

${ }^{80}$ I say "take form" rather than "follow" because the actual model that is learned may deviate from the original in a variety of ways. I discuss this phenomenon in the next section, where I describe the concept of "slippage." See infra notes 104-10 and accompanying text.

81 The process can be largely unconscious, as with parenting. On other occasions, the process can be explicit and directive, as when parents say: "Why can't you be more like Johnny?" Through such exemplars and paragons, we learn a great deal of normative information about how to evaluate behavior in a wide range of personal and professional circumstances:

We also comprehend categories in terms of individual members who represent either an ideal or its opposite. . . . Scientific paradigms are also characterized by paragons. Thus, for example, the Michaelson-Morley experiment is the paragon of physics experiments-and is used by many people to comprehend what a great experiment in physics is.

A great many of our actions have to do with paragons. We try to emulate them. We are interested in the life stories of great men and women. We use paragons as models to base our actions on. We have a great deal of interest in experiencing paragons .... We are constantly acquiring knowledge of paragons and regularly base our actions on that knowledge.

G. Lakoff, Women, Fire, and Dangerous Things: What Categories Reveal ABOUT THE MIND 87-88 (1987).

82 Winter, supra note 79 , at 1487.

83 See M. Merleau-Ponty, The Phenomenology of Perception 455 (C. Smith trans. 1962) ("I am a psychological and historical structure, and have received, with existence, a manner of existing, a style. All my actions and thoughts stand in a relationship to this structure .... .).

${ }^{84}$ Cf. Dan-Cohen, supra note 23, at 1656 ("[T]here are pretty clear social norms that regulate role-distance in these instances. To be a parent, characteristically, is to enact a non-detached role."). 
self has introjected that role and made those requirements its own. ${ }^{85}$

Much of this is familiar to us as the concept of a role model. We frequently miss the more profound implications of the concept, however, because we think of a role model as something external to the self. Yet, the power of a role model is internal-as we experience when we suddenly find ourselves sounding just like our parents or, in a moment of self-conscious reflection, we realize that the way in which we taught a class, made a point, or handled a question was exactly the way in which a favorite or influential teacher would have done it. It is in just this way that the self is constituted by and cannot be separated from its roles and other models. A "self" is a thickly textured complex of learned modes of interaction with the physical and social world; both the "self" and its "roles" are largely matters of what in psychology is called "internalization. ${ }^{86}$

This emphasis on internalization seems to run counter to what is intuitively correct about the distinction between detached and non-detached roles: Some roles are more peripheral to and others

${ }^{85}$ Here, then, is our first example of slippage. Dan-Cohen uses an example of a father who comforts his child. This is consistent with contemporary practice. Yet, most of us had fathers who left the bulk of nurturance to our mothers. Thus our contemporary idea of fatherhood includes actions that were formerly confined to motherhood. But, since we men also had mothers, we have an experiential base for assuming a more nurturant role. See $\mathbf{N}$. CHODOROW, THE REPRODUCTION OF MOTHERING: PSYCHOANALYSIS AND THE SOCIOLOGY OF GENDER 218 (1978) ("Anyone who has good primary relationships has the foundation for nurturance and love ...."). When as adults we come to see traditional gender roles as wrong and inegalitarian, we can draw upon our childhood experience of having been "mothered" to begin to reformulate our sense of a father's role.

Even so, old models-like old habits-do not simply disappear. From the standpoint of our conscious normative commitments, we can make use of our earliest experience of nurturance to begin to reformulate traditional roles. But we cannot transform entrenched ways of being-in-the-world solely by this act of will. See id. at 215 ("The sex-gender system is continually changing, as it responds to and affects other aspects of social and economic organization. Yet it stays the same in fundamental ways."). In fact, we know-or, rather, women know-that change in these deep-seated social roles comes much more slowly. See Belkin, Bars to Equality of Sexes Seen as Eroding, Slowly, N.Y. Times, Aug. 20, 1989, \& 1, at 1, col. 1 ("Men, while generally expressing support for women's pursuit of equality, said there had been more changes than women saw, with less cost to women than women reported. They suggested they had overcome sexism more thoroughly than women acknowledged, and they saw less need for further changes than women did.").

For a further discussion of the "adversity" that afflicts efforts at social transformation and its relationship to a theory of the subject that recognizes the "sedimentation" of thought, see Winter, supra note 79, at 1485-1505.

86 See R. SCHAFER, ASPECTS OF INTERNAIJZATION 8-16 (1968). 
more constitutive of one's sense of self. But the contradiction is only apparent, an entailment of the peculiar spatialization of self and role. We need not think of internalization as an in-or-out, allor-nothing process-either I internalize a role and it becomes "me" or it remains outside and detached-as if the self were just an empty container to be filled by its roles. Rather, the point of seeing the self as a complex of modes of interaction is to understand that any given role is just one of the many modes of interaction that make up the thick texture of the self. The distinction between detached and non-detached roles that we do experience is a function of what is internalized. Some roles, like that of a bank customer, ${ }^{87}$ are in their very acquisition taken on as only superficial aspects of the self. Others, like parenthood, are assimilated as integral to the self. This variability in role acquisition is not an essential characteristic of particular roles. Rather, the difference that we experience in the centrality or marginality of our various roles is a function of factors like role-duration, role-motivation, and the timing and method of role-acquisition. The role of bank customer, for example, is relatively episodic and incidental to the main concerns of one's life. Conversely, a role that is expressly intended either to organize large portions of a person's life (as when one becomes part of a profession) or to give it meaning (as when a profession is also a vocation) is more likely to become integral to the self. So, too, roles acquired in early childhood (as in the case of parenting) and basic modes of interaction (whether one is characteristically passive or aggressive, interactive or withdrawn) vill become deeply entrenched and constitutive of one's self.

From this account of every self as necessarily a situated-self with a particular social history, one might conclude that every self must be a "unique" individual whose "content" is entirely contingent upon its peculiar life experiences. But this conclusion would mistake social construction for solipsism. The roles and other modes of interaction that constitute the "self" are acquired through interaction with others who themselves, in turn, have acquired those roles in the same way. Thus, the interactions necessarily take place in an already existing social context in which the actions and roles are already endowed with social meaning. ${ }^{88}$ In this sense, all social

${ }^{87}$ Cf. Gabel, supra note 29, at 1567-68 ("As I move toward [the teller] from my place in line, I feel myself becoming a 'customer' of 'the bank' . . . ").

${ }^{88}$ See P. BERGER \& T. LUCKMANIN, supra note 17 , at 54 ("[E]ven . . . a solitary individual . . . will habitualize his activity in accordance with biographical experience 
roles are like MacIntyre's notion of character in that "a knowledge of the [role] provides an interpretation of the actions of those individuals who have assumed the [role]. It does so precisely because those individuals have used the very same knowledge to guide and to structure their behavior. ${ }^{289}$ It is for this reason that the end product is best described as a "kind of self."

This means that what binds one person to another in a community is not the attachment between their respective non-detached roles, but rather the fact that they share the same way of understanding each other's performance of those roles and other modes of interaction. That is, they have learned and therefore share common ways of understanding and living in a world. They maintain this community by their mutual enactment of these roles or by their complementary and reciprocal engagement on the basis of these understandings. ${ }^{91}$ There is, therefore, no separation between the self and its communities. ${ }^{92}$ Self and community are mutually constitutive.

\section{PUtTING COMmUNITY BACK INTO COMMUNICATION}

I have, so far, focussed on processes of internalization and said very little about the role of imagination. Imagination has nevertheless been an implicit part of the account. Once we have made the connection explicit, we will have established why normative practice is necessarily contingent upon community.

I complete the argument in the subsections that follow. First, I show why an understanding of a role as a mode of interaction with a community of others leads to the conclusion that internalization is an imaginative process. I then explore the implications of this insight for the concept of community. The introduction of imagination into the account provides the basis for a more realistic, robust picture of community that explains the inevitable plurality

of a world of social institutions preceding his solitude ...."). There is, however, nothing fixed, objective or invariable about this social meaning. This is the significance of the concept of "slippage" discussed below.

${ }^{89}$ A. MACINTYRE, supra note 33 , at 27.

${ }^{90}$ See supra note 83 and accompanying text.

91 See Winter, supra note 79, at 1488-89.

92 See M. MERLEAU-PONTY, SENSE AND NON-SENSE 128-29 (H. Dreyfus \& P. Dreyfus trans. 1964) ("Society for man is not an accident he suffers but a dimension of his being. He is not in society as an object is in a box; rather, he assumes it by what is innermost in him."); see also Winter, supra note 15, at 1135 ("[C]ulture is both 'in' us and that which we are embedded within."). 
within any community. But, at the same time that we find that imagination plays an indispensable part in the maintenance of community, we will find as well that community is essential to the coherence of normative practice.

\section{A. Internalization and Imagination}

Although it is conventional to speak of a role as something that can be "acquired" and "internalized," it is important not to make the mistake of reification. ${ }^{93} \mathrm{~A}$ role is not a unitary, static, or invariable "thing" but a dynamic pattern of conduct. The function of a role is to shape an array of interactions with others-parent with child, professor with students, corporate manager with subordinates-under conditions that vary in their particulars from circumstance to circumstance. It follows from this that internalization cannot be a matter of linear representation or simple reproduction. For if it were, the "object" of this introjection could not enable the kind of subsequent adaptive behavior that is characteristic of a role.

We can see this even at the level of one of the constituent practices that, together with many others, might comprise a role. When, for example, we initiate a child or a student to a new practice like swinging a bat or writing a brief, we say "Do it like this" and not "Mimic me motion for motion [or line for line]." If our pupil tries to reproduce our motions or style exactly, we know that the result will be woodenly self-conscious and not at all like what we are trying to impart.

Initiation is the difficult process we know it to be precisely because an adaptive, interactive practice like batting or brief-writing is not a determinate set of actions that can be reproduced in a mechanical, point-for-point fashion. To connect with the ball, the batter must coordinate her swing in response to the actions of the pitcher and to her perceptions of the velocity and trajectory of the ball. Similarly, the advocate must structure her arguments in response to those of an opponent while simultaneously taking into account the available interpretations both of the facts and of the legal doctrine that will be credible and persuasive to the decisionmaker. As a consequence, there can never be an exact correspon-

${ }^{93}$ For a discussion of the cognitive metaphors that structure this way of conceptualizing ideas and of the epistemic dangers of failing to recognize their metaphoricity, see Winter, Death Is the Mother of Metaphor (forthcoming 1991) (on file with the author). 
dence between that which is internalized and that upon which the internalization is based. To the contrary, initiation is a matter of repeated practice precisely because what the beginner is trying to learn is an abstraction of the teacher's actions: a way in which she can act effectively under similar-which is also to say slightly different-circumstances. What the beginner seeks is a model for subsequent behavior.

The usefulness of a model is that it can be extended to new and different contexts. ${ }^{94}$ Thus, the process by which we acquire and extend models can only be described as imaginative. ${ }^{95}$ This is so in two different senses. First, it is imaginative in the sense that it is not.merely representational but involves generalization or schematization, enabling the extension and application of a model to diverse particulars. Second, and more basically, it is imaginative in the sense that the process of acquiring and extending a model is to a large degree imagistic. ${ }^{96}$ Whether one is learning a model or applying it, the basic capacity that one is using is the ability to recognize patterns. ${ }^{97}$ Thus, one "has" a model only when one is able to recognize in the teacher's actions a pattern that does not depend on the detailed particulars of the original. With that knowledge "in hand," the person is then able to recognize other

94 Much the same is true of language. To learn a language is to acquire the ability to use words in many different contexts, which is one reason that language cannot be a matter of one-to-one correspondence with a world (or even with a world as specified under one set of culturally relative descriptions). Instead, linguistic phenomena are better accounted for in terms of the extension of imaginative devices such as metaphor, metonymy, and idealized cognitive models. See G. LAKOFF, supra note 81 , at 68-114, discussed in Winter, supra note 15 , at 1142-59.

95 The concept of "imagination" invoked here is not the conventional understanding of imagination as a random, innovative, originary capacity. Rather, I am drawing on a growing body of empirical and theoretical work that points to the conclusion that the human brain processes information imagistically and crossmodally. See G. Edelman, The Remembered Present: A Biological TheORY of CONSCIOUSNESS (1989); M. JOHNSON, THE BODY IN THE MIND: THE BODILY BASIS OF MEANING, IMAGINATION, AND REASON (1987); see also S. KossYLN, IMAGE AND MIND 317-406 (1980) (describing the use of visual images as a tool of cognitive abilities).

${ }_{96}$ The imagistic is "independent of any particular sensory modality" and extends beyond the visual to include the kinesthetic and spatio-temporal such as position, orientation, shape, movement, and velocity. G. LAKOFF, supra note 81 , at 445 . The cross-modal nature of these "images" has been demonstrated by mental imagery experiments conducted with people blind from birth, which have replicated the results obtained with sighted subjects. See id. at 445-46.

97 "[W]e do not have pure unstructured perceptions and images. . . . In perceiving and in forming images, we impose a great deal of image-schematic structure. It is this image-schematic structure that allows us to categorize what we perceive." Id. at 455 . 
circumstances as "similar" and to reenact the practice or role in a manner appropriate to the specific circumstances.

It may seem that the idea that images and patterns are central to the process of model acquisition is applicable only to purely physical skills like batting and not to more abstract cognitive operations. But the argument is the same in both cases: To the extent that "higher" order: processes like conceptualization and categorization are adaptive-that is, enabling successful application to contingent and changing situations-they must be associative and analogical. It follows that these processes are also structured by means of models, or related cognitive operations not dependent on content and correspondence. ${ }^{98}$

Recent advances in cognitive theory suggest that the very capacity of the brain to recognize patterns and form concepts depends on these imagistic structures of bodily experience and their cross-modal linkages in neural processes. ${ }^{99}$ These basic imagepatterns or schemata provide the predicate for conceptual metaphors that organize diverse areas of human interaction. Thus, for example, the very idea that a role can be "seen" as a "pattern" of actions is a metaphoric schematization of otherwise discrete actions and relations. Even highly abstract conceptual skills like legal writing and reasoning are structured by these image-based conceptions. We have seen one example in Dan-Cohen's spatialization of the concepts of "self" and "role," 100 and much the same can be

${ }^{98}$ If one could define the right logical connections, conceptualization and categorization could be a matter of necessary and sufficient criteria. But the evidence against that view is substantial. S'e id. at 12-57, 136-52, 185-205. In any event, no such view is possible without a vorkable correspondence view of meaning. See Winter, Bull Durham and the Uses of Theory, 42 STAN. L. REv. 639, 650-51 (1990).

99 Edelman explains some of these advances:

[B]ecause concepts are considered to require the mapping (and therefore the classification) of global mappings, the use of image schemata related to bodily states in the organization of thought and language is an expected characteristic in conscious organisms. Image schemata involve concepts connected to positions or states of the body as it relates to objects or events-for example, "obstacle," "resistance," "object," "motion," "containment," and "blockage." The evidence that image schemata are developed in humans comes from the classic studies of Head and from more recent analyses like those of Johnsor and of Spelke. Such schemata, frequently reflected as metaphors in the language of Homo sapiens, may already function in animals with conceptual capabilities and primary consciousness.

G. EDELMAN, supra note 95, at 195 (footnote omitted) (discussing M. JoHNSON, supra note 95; Spelke, The Origins of Physical Knowledge, in THOUGHT WITHOUT LANGUAGE 168 (L. Weiskrantz ed. 1988)).

${ }^{100}$ See supra notes $61-78$ and accompanying text. 
demonstrated with more classic examples of conventional legal reasoning. ${ }^{101}$

Notwithstanding their origin in embodied action, these imageschemata (and, a fortiori, their metaphorical extensions) are neither biologically innate nor predetermined. They are, rather, learned through interaction with one's physical and social environment. ${ }^{102}$ It is their repetition and reenforcement through bodily experience that gives them their potency as organizing schemata. At the abstract level, much the same is true for the extended metaphors and models that they structure; as these models are successfully enacted in social life, they gain a measure of psychological "solidity" as a consequence of the confirmation and reenforcement received from others. ${ }^{103}$ This provides some further insight why initiation into a role is neither automatic nor mechanical and linear, but must be experienced and practiced.

Let me summarize what we have accomplished so far. An understanding of a role as a mode of interaction with others necessarily implies that a role is not a determinate "thing," but rather a dynamic, adaptive pattern of actions and responses. Consequently, to speak of a role or a model as something that is internalized is just a conventional way of describing a more complex process that is necessarily imaginative. To acquire a role, one must abstract from practice, repetition, and experience a generalized, imagistic pattern of behavior that does not correlate with the original in a one-to-one fashion.

101 For example, the structure of Chief Justice Hughes's reasoning in NLRB v. Jones \& Laughlin Steel Corp., 301 U.S. 1 (1937), turns on the source-path-goal schema and the metaphors for commerce that he is able to elaborate from it. See Winter, supra note 15, at 1199-1206. For a discussion of how the general category of "narrative" and the subcategory of "argument" are both structured in terms of a few basic image-schemata, see Winter, The Cognitive Dimension of the Agon Between Legal Power and Narrative Meaning, 87 MICH. L. REV. 2225 (1989).

102 See G. EDELMAN, supra note 95, at 167 ("[T]he density, relationships, and character of such 'images' are determined practically completely by interactions with the world and its objects and arrangements."); M. JOHNSON, supra note 95, at 29 ("These patterns emerge as meaningful structures for us chiefly at the level of our bodily movements through space, our manipulation of objects, and our perceptual interactions.").

${ }^{103}$ See M. MERLEAU-PONTY, supra note 83, at 441 ("[W]e must recognize a sort of sedimentation of our life: an attitude towards the world, when it has received frequent confirmation, acquires a favoured status for us."). 


\section{B. Slippage}

I have argued that there is never an exact correspondence, but rather an imaginative relationship between the model that is internalized and the behavior that it is modeled upon. If this is correct, it means that the processes of cultural learning and reproduction are characterized by slippage. ${ }^{104}$ If we conceptualize a community as a group of people who share common ways of understanding and living in a physical and social world, then the existence of slippage will mean that community is necessarily a relative phenomenon characterized by degrees of plurality and divergence.

Some of the causes of slippage can be readily described. ${ }^{105}$ Suppose that all the parents in a community shared precisely the same idealized conception of parenthood. Their children would nevertheless derive somewhat different models of parenthood for at least three reasons. First, it is unlikely that the first generation would have enacted the parental role in precisely the same idealized form-at least given what we know about human fallibility and the variability in talents, intelligence, and the like. Second, even if all the parents in the first generation were equally capable, they still would not enact the parental role in precisely the same way. During the course of raising their children, these parents would inevitably confront different circumstances that require innovation in their enactment of the parental role. This follows from the concept of a role as a pattern of adaptive behaviors:

Human rationality is a dynamic process of meaningful interaction in and with an environment that is constantly in flux. Which is to say that, whatever our "built-up predispositions," we inevitably encounter situations that we "have previously never met or thought of." In this context, to react along the lines marked out

${ }^{104}$ In his contribution to this symposium, Pierre Schlag uses the term "slippage" differently to describe the phenomenon in which the assumptions and beliefs that are consciously held with regard to one intellectual domain are unconsciously projected into and reproduced in another, putatively separate, domain-i.e., that they "slip into" another supposedly unrelated set of social interactions. Slippage of this sort also occurs from the intellectual to the material domain and back again as the assumptions that are inscribed in material conditions influence and structure concept formation. See Schlag, Normativity and the Politics of Form, 139 U. PA. L. REv. 801, 909-11 (1991). $I$ would discuss these phenomena in terms of projection, transference, and sedimentation. See Winter, supra note 79, at 1487-92.

105 There are forms and causes of slippage other than those I describe below. For an example, see supra note 85 and accompanying text. 
by our sedimented knowledges is unavoidably to act imaginatively in a new circumstance, reasoning in terms of a known one. ${ }^{106}$

Consequently, the social experiences from which different members of the second generation will abstract their models of the parental role will not be exactly the same.

Third, there is no determinate regularity in the process of internalization by which the second generation gains its models of parenthood. The chief attribute of a model is that it is an imaginative abstraction from, and not a mere reproduction of, the original behavior upon which it is based. Thus, even if all the parents in the first generation enacted their roles in the same way, the models internalized by the second generation would not necessarily be identical. ${ }^{107}$ For example, some members of the second generation will form models that are reactive rather than imitative. ${ }^{108}$ Thus, there would be slippage even if the underlying social experiences were somehow exactly the same.

If we combine even these three forms of slippage and multiply the effects across several generations, the result will be a group that no longer shares precisely the same idealized conceptions of parenthood that once characterized their forebears as a community. The cohesiveness of the successor group will be a function of the degree of similarity remaining among the surviving conceptions of the parental role. We can nevertheless expect that there will be some degree of similarity, and not rampant incommensurability, for several reasons. First, much about the enactment of the parental role will remain the same despite changes even in important particulars: By and large, parents will still be feeding and changing their babies, responding to them when they cry, etc. Second, because a model is an imaginative abstraction and not a copy, not every difference in the content of the parent-child experience will yield dissimilar internalizations. ${ }^{109}$ Third, to the extent that there

106 Winter, supra note 79, at 1491 (footnote omitted) (quoting Llewellyn, The Constitution as an Institution, 34 CoLUM. L. REV. 1, 27 (1934)).

${ }^{107}$ Cf. N. CHODOROW, supra note 85, at 216-17 ("Psychoanalysis does show that we are formed in crucial ways by the time we are five, but it ... argues against a unilateral model of social determination, and for the variation and creativity in what people make of their early childhood experiences . . . .n).

${ }^{108}$ Cf. Winter, supra note 98, at $650 \mathrm{n.57}$ ("It is rather like the analysand who rejected the therapist's insight that she was powerfully influenced by her mother. 'That's not truel' she said. 'I am nothing like my mother. In fact, I am exactly the opposite!'").

109 This is the flip side of the phenomenon of "nondeterminacy"-that is, the way in which a single image-based model can structure very different substantive 
are dissimilarities in their models of the parental role, every set of parents will have to work out some accommodation between them; as a result, their enactment of the parental role will tend to converge upon what is similar or complementary in their internalizations. ${ }^{110}$ Fourth, and in much the same vein, any set of parents will interact with a variety of other social actors and receive substantive input from many different social sources-their own parents, the children's teachers, state gun control statutes-that will shape and constrain their enactment of the parental role along common or complementary lines.

For these reasons, the processes of cultural learning and reproduction will be characterized by slippage rather than outright incommensurability. This means that different members of the community should be able to interact in a meaningful manner despite the differences in their internalized models. But, there will be gaps between them-gaps of understanding, discrepancies of values, lacunae in performance. A clash between these competing modes of interaction will open a normative space that must be bridged. What conditions will best foster resolution of these conflicts?

It would seem that, in answering this question, one must first know which tack the participants will take. Will they be oriented strategically toward success or will they be more ambitious and try to reach agreement through dialogue and understanding? Suppose the participants opt for strategic interaction. The more each participant knows about or is able to appreciate the other's understandings, values, and resulting perspective, the better positioned she will be to manipulate the other successfully and achieve her strategic objective. If one participant is self-conscious and reflective about her knowledge of the other, she will have a substantial advantage in their interaction even when their knowledge of each other is equal. By the same token, if they each try selfconsciously to use their knowledge of the other to strategic advantage, but they possess only imperfect knowledge of the other, the strategic advantage will lie with the participant with the better understanding of the other's perspective. In either case, the more knowledge one has of the other's animating models, the better she

outcomes. See Winter, supra note 101, at 2230-55.

110 Of course, one partner may dominate, imposing upon the other's model. But this will tend to reduce slippage-and skew social evolution along different linesbecause in the case of any such family only half of the models will be enacted. 
will be able to identify pressure points within the antagonist's perspective that can be exploited to effectuate her strategic goal.

The availability of this knowledge of the other will be a function both of the degree of slippage within the community and of its pervasiveness. To the extent that the antagonists share substantially similar models of the subject of their interaction, they will be able more easily to apprehend the other's perspective on and understanding of the conflict. Even if the slippage here is great, they may nevertheless share many other models, values, and understandings that are relevant to and can be brought to bear upon this conflict. If, however, the gaps are great and slippage pervasive, this knowledge must be sought through an imaginative attempt to reconstruct and apprehend the antagonist's point of view. The more one can discover about one's antagonist-her life experiences, her previous actions, her articulated understandings-the better one will be able imaginatively to reconstruct her perspective and use this knowledge to strategic advantage.

Suppose that the participants take the high road and seek agreement through understanding instead. The less slippage, the more cohesive the community, the more easily will they be able to bridge the normative space between them. If the slippage is great with respect to their models of the interaction in question, their ability to reach consensus will be a function of the relative cohesion with respect to the other models and values that bear upon their conflict. ${ }^{111}$ But, once again, if slippage is both substantial and pervasive, then it will require an act of imagination in order to bridge the gaps and achieve accord. ${ }^{112}$

${ }^{111}$ Cf. Felstiner, Influences of Social Organization on Dispute Processing, 9 LAW \& SOC'Y REV. 63, 74 (1974). Felstiner notes:

Mediation ... flourishes where mediators share the social and cultural experience of the disputants they serve, and where they bring to the processing of disputes an intimate and detailed knowledge of the perspectives of the disputants. In the absence of such shared experience and such pre-processing knowledge, the effort a mediator would have to make to fill the gaps would be disproportionate to the social stakes involved in the dispute.

Id. (footnote omitted).

Felstiner also points out that the importance of understanding context and perspective is increased if one sees conflicts not merely as a matter of conflicting role expectations but rather as a process in which "individuals . . . continually redefine themselves and their situations and realign their behavior accordingly." Id. at 74 n.16.

${ }^{112}$ For an example, see Winter, supra note 101, at 2279. 
Agreement may be facilitated by imagination in another way. If the community is in fact cohesive, then the participants may share a commitment to empathize and identify with each other. This may lead them first to explore and ultimately to appreciate the perspective of the other. Indeed, this experience of mutual recognition and shared identification is probably the most salient characteristic of what we ordinarily take to be a community. Thus, to return to DanCohen's example, ${ }^{113}$ parents normally are moved to thank the person who helps their child to cross the street precisely because a benefit to one's child is experienced as if it were a benefit to oneself. One does not do so "by virtue of my parental role, and as an aspect of it ...."114 Rather, one thanks the benefactor by virtue of and because the very "self" of the parent is bound up with the well-being of his or her children. Parents identify with their children, feel their pain, and experience their joy. Indeed, they are motivated to act for them as if they were acting for themselves.

It may be rare to find this degree of empathy and community outside the ideal family, but the point is that it is just this form of identification and vicarious imagination that provide a group with a self-conscious sense of community and solidarity. And this identification comes most easily with respect to others who share with us common ways of understanding, acting, and living in a world. Which means that the resolution of normative conflict by means of communitarian efforts at agreement through understanding will be most effective when it takes place in the context of already existing community.

You will have noticed, no doubt, that whether the participants set out to resolve their controversy through strategic interaction or through dialogue and "communicative action," the conditions of success are exactly the same. In either case, effective and efficient resolution will be a function of the degree to which they share internalizations and the capacity for imagination. In either case, community is the practical precondition for meaningful communication.

This leaves us with only the final and, by this point, all too obvious step of the argument. As we already know from DanCohen, prescriptive normative practices like adjudication are conventionally understood as primarily strategic forms of communi-

113 See supra notes 73-74 and accompanying text.

114 Dan-Cohen, supra note 23, at 1662. 
cation. Conversely, persuasive normative practices like Michelman's republican jurisgenesis are the political forms of communicative action. Both are contingent on community.

\section{THE CONTINGENCY OF COMMUNITY}

In our conventional understanding, community is a background condition of social order against which individual acts of deviance are measured. Deviance, in this view, is a failing of the self; prescription (i.e., the law) serves as the occasional corrective that provides the right "external" motivation. ${ }^{115}$ Instead, I have argued that community is located in and reproduced by a self that cannot be abstracted from its social context nor understood apart from it. Which means that deviance is not so much a problem of wayward selves as it is an index of the relative degree of slippage within a community.

Conventional normativity blames the self for processes that are themselves dependent upon achieving and maintaining the right kind of community. One need only look to the ghettos that so frequently are only a stone's throw from our law schools to observe the degree to which, in our society, slippage has become social hemorrhage. ${ }^{116}$ The problem may be represented by the "No Turn on Red" and gun control stories, but these are only the tip of the iceberg. If, at times, the coherence and intelligibility of normative practice within the legal academy seems in similar jeopardy, it is for exactly the same reason: Both inside and outside the ivory tower, the conditions of community that are necessary to maintain its coherence are everywhere in disarray. It is not too soon to say that we are threatened by fragmentation and social disintegration.

I do not expect that the normative impulse will go away, nor do I advocate that it should. But we are saddled by a futile and increasingly counterproductive model of social order. The salient

115 In Dan-Cohen's case, for example, a community is a monolithic system of tightly integrated non-detached roles within which persuasion should ordinarily suffice because "insofar as matters concerning the community go, the members occupy a common space ...." Dan-Cohen, supra note 23, at 1661. If there is discord within a real world community, then it must be because a gap has opened between one of its member selves and her putatively non-detached role. In that event, the fault lies with the self and must be corrected by prescription. The problem of contemporary normative practice is a problem of inducing the "proper" motivation of the self.

116 See Finnegan, supra note 1. 
advantage of the cognitive account of community is that it offers the potential of a more effective approach to normative practice. "Human society is not a community of reasonable minds, and only in fortunate countries where a biological and economic balance has locally and temporarily been struck has such a conception of it been possible."117 A conception of community as a set of shared understandings located in the self can focus more productive attention on fostering the kinds of conditions of community that might enable a more meaningful normative practice. If the vertiginous biological and economic imbalance in our society threatens the coherence of normative practice, then quite a bit more is at stake-including the very survival of our society as a democratic one. Fragmentation and democracy cannot coexist precisely because the common matrix is increasingly undone.

I have frequently argued that our linguistic and conceptual capacities are grounded in our physical embodiment. ${ }^{118}$ But if that is all we share, communication will be very difficult and rudimentary. To deal with the complex, intractable problems about which real law happens, we need a lot more to go on. My point is not that dialogue, persuasion, and normative practice are all impossible, but that their effectiveness is contingent upon community understood as a shared way of living in and understanding a world. ${ }^{119}$ This explains why my work keeps taking such a strongly communitarian turn. Ultimately, we must come to see it is our similar embodiment and shared social situatedness that jointly provide the common grounds upon which the work of empathy can-and must-be done.

117 M. MERLEAU-PONTY, supra note 83, at 56 .

${ }_{118}$ See, e.g., Winter, supra note 15, at 1129-50.

119 See Michelman, supra note 21, at 1513 ("The persuasive character of the process depends on the normative efficacy of some context that is everyone's-of the past that is constitutively present in and for every self as language, culture, worldview, and political memory."). 